\title{
Factors Influencing Women's Preferred Mode of Delivery in Kericho County Hospitals, Kenya
}

\author{
Caroline Chelangat $^{1}$, Mary Kipmerewo ${ }^{2} \&$ Beatrice Mukabana $^{2}$ \\ ${ }^{1}$ Graduate student: School of Nursing, Midwifery and Paramedical Sciences: Masinde Muliro University of \\ Science and Technology, Kenya \\ ${ }^{2}$ Lecturer, School of Nursing, Midwifery and Paramedical Sciences, Masinde Muliro, University of Science and \\ Technology, Kenya \\ Correspondence: Caroline Chelangat, Graduate student: School of Nursing, Midwifery and Paramedical Sciences: \\ Masinde Muliro University of Science and Technology, Kenya.
}

Received: July 30, 2021 Accepted: October 1, 2021 Online Published: October 28, 2021

doi:10.5539/gjhs.v13n11p89 URL: https://doi.org/10.5539/gjhs.v13n11p89

\begin{abstract}
Purpose: To evaluate the factors influencing women's preferred mode of delivery among postnatal mothers in Kericho County Hospitals.

Methodology: Descriptive cross-sectional design was adopted and mixed methods used for data collection. A total of 310 participants were randomly selected using a systematic sampling for quantitative and qualitative approach that used Focus Group Discussion among postnatal mothers in both sampled private and public facilities of Kericho County Hospitals. Data entry and analysis was done with mean and standard deviation computed with results presented in tables. The study used descriptive and inferential statistical analysis. To determine association of variables bivariate and multivariate logistic analysis was adopted. Odds ratios were calculated and the p-value of $<0.05$ was considered statistically significant.
\end{abstract}

Findings: The preferred mode of delivery by most respondent was vaginal delivery at $81.3 \%$ and $18.7 \%$ wanted caesarean section. Bivariate analysis of variables showed that level of education $\mathrm{p}=0.002$, marital status $\mathrm{p}=0.0001$, occupation $\mathrm{p}=0.007$. Cultural beliefs that prohibit certain mode of delivery among postnatal mothers had statistical significant of $\mathrm{p}=0.02$. With focus group discussion, a major concern for almost all women was the severity, duration and patterns of labor pains.

Unique Contribution of the Study: The study results showed that health provider's attitudes, care and support influenced their mode of birth. Most respondents showed confidence of been delivered by midwives as compared with other carders Cultural beliefs that prohibit certain mode of delivery was a variable that had significant association with preferred mode of delivery with a value of $p=0.02$. The findings will be useful in designing interventions and strategies that focuses individualized care of mothers during childbirth to meet individual needs and expectations.

Keywords: women, preference, mode of delivery/birth, vaginal delivery, caesarean delivery

\section{Introduction}

Pregnant women are normally involved in decision-making process concerning mode of delivery and many factors affect their decision. These processes are influenced by person's environment, values, personality, knowledge and insight which influence each other interactively (Zakerihamidi et al., 2015). The 'vaginal birth' process is recognized as an undeniable mode of birth in all parts of the world. Childbirth is considered a significant women's occurrence and the rising numbers of maternal C-section demands contribute to women's expectations that C-section is a safer mode of birth. Women's childbirth satisfaction as a quality indicator for maternal care is assessed in various dimensions: childbirth experience \{pain severity, labor complications and duration\}, medical and nursing knowledge obtained, decision-making involvement in processes, physical aspects. The models of maternity care influence the mode of delivery; one is biomedical where technological development in obstetric field has changed childbirth by slowly replacing home deliveries with hospital and giving birth has been medicalized (Garthus, Soest, \& Knoph, 2014). The other model is the humanized model according to WHO (2012) the woman giving birth is placed at centre and is in control of process to promote active participation of the mother. 
Humanizing birth means considering women's belief, values, feelings and respecting their autonomy and dignity during the birthing process.

Other influences on women's chosen mode of delivery and birth are women's role in decision- making, appreciation for the partner's involvement, physical conditions and pain. Most women tend to get vaginal birth, $5-20 \%$ prefer C-section in countries with high incomes and $1.4-5 \%$ in the countries with low middle incomes. The highest caesarean rates in Latin America and the Caribbean have been $40.5 \%$, followed closely by North America (32.3\%), Oceania (31.1\%), Europe (25\%), Asia (19.2\%) and Africa (7.3\%) (Betran et al., 2016). The six factors associated with preferred mode of delivery include: perceptions of safety, fear of pain, previous birth experience, encouragement and discussion from health care workers, social and cultural influences and access to information and education levels. Caesarean delivery on maternal request has increase due to fear of episiotomies, long and painful labor, pelvic floor trauma and subsequent incontinence associated with vaginal birth (Wang, Tan, \& Kanagalingam, 2013).

The renewed efforts under the Sustainable Development Goals (SDGs) agenda has special focus on ensuring provision of quality maternal and new-born care that is both clinically appropriate and delivered in respectful and dignified manner. The main agenda of SDGs is to reduce maternal mortality to less than 70 per 100,000 (UNFPA, 2014). People's decision making regarding health-related issue is based on beliefs and their perceptions (Hameed, 2018). In Sub-Saharan Africa maternal mortality ratio remains high attributed to factors associated with mode of delivery. Pregnancy and childbirth continue to be viewed as solely women's issues (Magoma et al., 2014). For example, results from a study conducted in Nigeria indicated that caesarean section accounted for $14 \%$ of all deliveries of which $90 \%$ were emergency yet caesarean was not the preferred mode of delivery by most of the women contributing to poor prenatal outcomes. In Kenya delivery by caesarean section ranges between $10-14 \%$ on average with barriers existing on choice preferred mode of delivery (KHDS, 2014).

A number of studies on factors affecting women's preferred mode of delivery have identified multi-factorial causes. Such factors include, not limited to interpersonal factors such as mother's prenatal trauma and obstetric factors such as inadequate pain control, resulting to emergency caesarean section and assisted vaginal delivery contributing to negative childbirth outcomes (Karlstorm, Nystedt, \& Hildingsson, 2011). Mothers who perceive a supportive and safe environment from their health care providers during childbirth felt empowered to explore and make decision regarding their mode of delivery resulting in positive birth outcome. Women's preferences for mode of delivery are reported to be influenced by culture, knowledge of risk and benefits, personal and social factors. Reason's for women's preferences ranges from perceived ease of recovery and need to return to family responsibilities (Karlstrom, Nystedt, \& Hildingsson, 2015).

Determining their preferences in mode of delivery will help reduce the maternal and prenatal morbidity and mortality (Brodrick, 2014). Advancement of delivery care including caesarean delivery has greatly improved the outcomes of birth globally with significant reduction of maternal morbidity and mortality. However, the evidence to support this is limited in Africa especially Kenya and more particularly, in the study area. The study aims at examining the factors influencing women's preferred mode of delivery. However, no similar studies have been undertaken in Kenya and more so in multicultural area such as Kericho County with mothers from various ethnic backgrounds seeking delivery service in public and private health facilities.

\subsection{Statement of the Problem}

According to the District health information system for Kericho (DHIS, 2019) most women prefer normal delivery which is associated with less complication. On the other hand, C-section delivery is also utilized well however it is associated with; poor perinatal outcomes to include neonatal deaths, postpartum hemorrhage, wound sepsis and even maternal mortalities. Most women feel stressful when determining the form of childbirth and are influenced by factors such as terror, anxiety, compassion and a rational approach. Therefore, the study aimed at examining the factors influencing women's to preferred mode of delivery i.e. vaginal delivery versus caesarean section.

\subsection{Objectives}

\subsubsection{Broad Objectives}

To evaluate the factors influencing women's preferred mode of delivery in health care facilities in Kericho County.

\subsubsection{Specific Objectives}

1) To analyze the patient factors influencing women's preferred mode of delivery in health care facilities in Kericho County. 
2) To determine socio-cultural factors influencing women's preferred mode of delivery in health care facilities Kericho County.

\subsection{Null Hypothesis}

There is no relationship between patients, socio-cultural and health care provider factors influencing women's preferred mode of delivery in Kericho County, Kenya.

\section{Methodology}

\subsection{Study Design}

A descriptive cross-sectional study was conducted among postnatal mothers who were two months post-delivery at $\mathrm{MCH} / \mathrm{FP}$ clinics and those who had delivered at maternity units of sampled health care facilities in Kericho County facilities during the study period.

\subsection{Study Area}

The study was conducted in health care facilities in Kericho County which includes; Kericho County Referral Hospital, Litein Mission, Kericho Nursing Home and Siloam Hospitals. The county covers a total area of 2,479 sq.km with total population of 758,339 as per 2009 national population. It is divided into six sub-counties, thirty wards, eighty five locations and two hundred and nine sub-locations. The county population has multicultural setting with members from different communities and cultures such as Kipsigis, Kikuyu, Asians, Luos, Turkanas, Kisii and Lugha among others (KCSP 2014-2017).

The major source of income for the people of Kericho County comprises of produce from the farm products such as tea, pineapples, coffee, sugarcane, potatoes, maize and horticultural crops. There is also dairy farming practiced within the county. Employment by 33 multinational companies such as tea farms and factories is another major source of income. The informal sector and more specifically the Jua kali offers another form of employment (KCAP2019-2020).

The county has a fairly well-developed health infrastructure supported by both government and private service providers. The biggest challenge remains in the quality of care available in health facilities due to inadequate equipment's and personnel. Targeted indicators include doctor/nurse to patient ratio, maternal mortality rate, and infant mortality rate and under five mortality rate (KCSP 2014-2017). The facilities offer services such as preventive, curative and rehabilitative services. The county hospital has seven wards and special units of renal and intensive care units. It has a bed capacity of 270 with average outpatient cases of 4800 monthly and inpatient cases ranging from 2000-2500 monthly (DHIS, 2018).

The maternity department has three inpatient wards which include antenatal/labor, postnatal and new born unit with bed capacity of 57 and average bed occupancy of $85 \%$. The unit is managed by twenty-seven nurses, two medical officers and two consultants (DHIS, 2018). The average number of vaginal deliveries in a month is 450 and caesarean cases at an average of 70 monthly where emergencies caesarean is higher than elective (DHIS, 2018). The county hospital and other private hospitals are located in Ainamoi sub-county with catchment area population projected at $25 \%$ of women of childbearing age (15-49 years). This translated to a total of 22,921 and pregnant and deliveries projected at 3484 with 3.8\% population segment estimates (DHIS, 2018). Litein Mission Hospital is located in Bureti sub-county is the largest faith Base hospital that offers maternity services, preventive, curative and rehabilitative services in the county. The study was carried out in one public hospital that is Kericho county hospital, one mission facility Litein mission hospital, Kericho Nursing home and Siloam hospitals under the private sector.

\subsection{Study Population}

The study participants comprised of mothers who delivered in the sampled health care facilities in Kericho County during the study period. These enabled the researcher to gather information from mothers who had had their deliveries in different settings. The facilities were chosen based on the number of deliveries monthly with the least having hundred.

\subsection{Inclusion Criteria}

Inclusion criteria for this study consisted of: Postnatal mothers who delivered in the sampled health care facilities in Kericho County. Mothers who delivered through elective C-section and normal delivery within a period of two months to live singleton infant greater than or equal to 37 weeks gestation. Mothers who were two months post-delivery during study period at $\mathrm{MCH} / \mathrm{FP}$ clinics were included since they would remember their experience during childbirth. 


\subsection{Exclusion Criteria}

Women who delivered through emergency C-section, Women who had twin delivery. Women who had infants in new-born unit and those mentally unstable were excluded in the study and mothers giving birth for the first time.

\subsection{Data Collection Tools}

The researcher used two tools to collect data: structured questionnaire to collect quantitative data and Focus Group Discussion to collect qualitative data. The reseacher modified and adopted a questionnaire used by Dencker, Taft, Bergqvist \&Berg, 2010 and Hollins martins et al. 2010 that was used in hospital in sweden to evaluate factors influencing women's preferred mode of delivery. The modified areas include obstetric and health information of the mother, memories from childbirth and stress experience during labour and birth because it is not consistently used in the study area.

\subsection{Data Collection Procedure}

Training of two research assistant was done in one day and the topics included: verbal interpretation of the questions into local languages during training for uniform contextual understanding by all teams although this was not used during the interviews; Duties and responsibilities; Research ethics; Conducting mock interviews and Research logistics a pre- test of the research tools and procedures was conducted in selected facility that was not main study area after which the team met to review and share experience correcting the tool where necessary.

The Focus Group Discussion was run for 30-45 minutes where research assistant were orientated on the focus group guide that was used to collect qualitative data. The research assitant moderated the discussion and principal invistigator took notes on key issues during the discussion. A tape recorder was used to record information during the discussion for reference and clarity in case note taking miss out some points is this during data collection.

\subsection{Data Analysis}

Data from the completed questionnaires was coded, cleaned and, analyzed using Statistical Package for Social Science (SPSS) version 22. Mean and standard deviation was used to describe characteristics of participants. Bivariate analysis was used to analyze maternal socio- demographic characteristics that influenced the women's preferred mode of delivery. Multivariate logistic regression was performed to show association of the factors influencing women's preferred mode of delivery.

Qualitative information collected via FGD was analyzed through content analysis. Qualitative data was transcribed, interpreted and analyzed thematically according to the relevant objectives. The written interview was analyzed according to the objectives with common meanings, shared descriptions and expressions was identified by comparing and contrasting the text to allow the themes to emerge.

\section{Findings and Discussions.}

\subsection{Socio-Demographic Characteristics Influencing Women Preferred Mode of Delivery}

In this study, 310 respondents participated and response rate of $98 \%$ was achieved. Majority of the respondents 252 $(81.3 \%)$ preferred SVD and $58(18.7 \%)$ CS. More than half (60.3\%) of those who preferred SVD were aged $25-$ 34 years compared to $39.7 \%$ for CS. The difference between the two groups was not statistically significant ( $\mathrm{p}=$ 0.3 ). Mean age for each preferred mode was comparable with an overall mean of 27.1 and a SD of \pm 5.5 for those who preferred SVD and a range of $19-38$ years and mean age of 27 years and a SD of \pm 5.5 for CS group with a range of 20-36 years. Again, the difference was not statistically significant $(\mathrm{p}=0.8)$. The proportion of married women (92.4\%) with preference of SVD childbirth was significantly higher than single, separated or widows in the same preference category $(\mathrm{p}<0.0001)$. Other variables with significant results included level of education $(\mathrm{p}=$ 0.002 ) and occupation (0.007) with $85.3 \%$ of women in secondary school and $91 \%$ farmers preferring SVD. No significant results were reported among women living with partner, religion or income. For the two preferred mode of delivery, type of facility used, public or private did not yield statistically significant differences $(p=0.4)$ and hence no comparative analysis was required for the two groups.

\subsection{Maternal Socio-Demographic Characteristics by Mode of Delivery Preference}

Bivariate analysis was used to determine the association between maternal socio-demographic characteristics and preferred mode of delivery. Married women were 4.4 times more likely to prefer SVD than single, separated women or widows (OR: 4.4; 95\% CI: $2.2-8.6$; $\mathrm{p}<0.0001$ ). Likewise, those living with partner were four-fold more likely to have preference for SVD (OR: 4.1 ; $95 \%$ CI: $2.1-8.2$; $<<0.0001)$. Finally, women with less than KSh. 20,000 were $60 \%$ less likely to have liked SVD (OR: $0.4 ; 95 \%$ CI: $0.2-0.7 ; p<0.003$ ). This was not expected but could be explained by the fact that such women would also be having other sources of income that 
could have not been included in the monthly income. On the other hand, age group, level of education (primary/secondary vs tertiary) and religion, were not significantly associated with preference in mode of delivery. Married women living with their partners had statistical significant in terms of mode of delivery preference with $p$ value $<0.0001$.

\subsection{Cultural Factors Influencing Women's Preferred Mode of Delivery}

Culture-related social concerns may also influence the preferred mode of delivery. Four variables were tested to determine their association with the outcome. Table 1 illustrates the findings on cultural factors influencing women's preferred mode of delivery. Most of the respondents agreed that having cultural beliefs that prohibit certain mode of delivery was up to 4.5 times more likely to influence preference for SVD compared to women without such beliefs (OR: $2.2 ; 95 \%$ CI: $1.1-4.5 ; p=0.02$ ). A slightly smaller proportion of women who practiced FGM (84.6\%) in comparison to $86.1 \%$ who did not, intended to have SVD as preferred mode of delivery. The results were, however, not significant. Reports also show that slightly higher proportion of Luo women (86.1\%) preferred SVD than Kipsigis, Kikuyu and Kisii (84.6\%) women though the results were not statistically significant.

Table 1. Cultural factors influencing women's preferred mode of delivery

\begin{tabular}{|c|c|c|c|c|c|c|c|}
\hline Variable & Categories & $\mathbf{N}$ & $\begin{array}{l}\text { SVD } \\
\%\end{array}$ & $\begin{array}{l}\text { Caesarean } \\
\text { Section } \\
\%\end{array}$ & OR & $95 \%$ CI & $\begin{array}{l}\mathbf{P} \\
\text { value }\end{array}$ \\
\hline \multirow[t]{2}{*}{ Religion } & Christian & 272 & 84.9 & 15.1 & 1.1 & $0.4-2.7$ & 0.9 \\
\hline & Muslim & 38 & 84.2 & 15.8 & & & \\
\hline \multirow[t]{2}{*}{ Tribe } & $\begin{array}{l}\text { Kipsigis, } \\
\text { Kikuyu, Kisii }\end{array}$ & 267 & 84.6 & 15.4 & 0.9 & $0.3-2.2$ & 0.8 \\
\hline & Luo & 43 & 86.1 & 13.9 & & & \\
\hline $\begin{array}{l}\text { Have cultural beliefs } \\
\text { that prohibit certain } \\
\text { mode of delivery }\end{array}$ & $\begin{array}{l}\text { Yes } \\
\text { No }\end{array}$ & $\begin{array}{l}254 \\
56\end{array}$ & $\begin{array}{l}87.0 \\
75.0\end{array}$ & $\begin{array}{l}13.0 \\
25.0\end{array}$ & 2.2 & $1.1-4.5$ & 0.02 \\
\hline $\begin{array}{l}\text { Have cultural } \\
\text { practices like FGM }\end{array}$ & $\begin{array}{l}\text { Yes } \\
\text { No }\end{array}$ & $\begin{array}{l}226 \\
43\end{array}$ & $\begin{array}{l}84.6 \\
86.1\end{array}$ & $\begin{array}{l}15.4 \\
13.9\end{array}$ & 0.9 & $0.3-2.2$ & 0.8 \\
\hline
\end{tabular}

\subsection{Health Facility Factors Influencing Women's Preferred Mode of Delivery}

Table 2 presents selected heath facility factors influencing women's preferred mode of delivery. Women whose delivery were conducted by midwives were four times more likely to have preferred SVD than those delivered by obstetricians or clinical officers (OR: $4.2 ; 95 \%$ CI: $1.7-10.2 ; \mathrm{p}=0.0008$ ). Equally, important, women who had induction were almost thrice as likely to have preferred SVD compared with women who were not induced (OR: $2.7 ; 95 \% \mathrm{CI}: 1.4-5.1 ; \mathrm{p}=0.002$ ). No significant relationship was found between type of facility, type of induction, augmentation of labor, type of support for pain relief and preferred mode of delivery. Non- significant results notwithstanding, whereas more women $(82.5 \%)$ who delivered in public facilities intended to have SVD as opposed to $78.2 \%$ who visited private hospital, a smaller proportion had mechanical induction (81.2\%) augmentation of labor (71.4\%) as opposed to $91.4 \%$ who had pharmacological induction and $75.5 \%$ who did not have augmentation of labor. 
Table 2. Health facility factors influencing women's preferred mode of delivery

\begin{tabular}{|c|c|c|c|c|c|c|c|}
\hline Variable & Categories & $\mathbf{N}$ & $\begin{array}{c}\text { SVD } \\
\%\end{array}$ & $\begin{array}{c}\text { Caesarean Section } \\
\%\end{array}$ & OR & $95 \%$ CI & $P$ value \\
\hline \multirow{2}{*}{$\begin{array}{l}\text { Type of } \\
\text { facility }\end{array}$} & Public & 223 & 82.5 & 17.5 & 1.3 & $0.7-2.4$ & 0.4 \\
\hline & Private & 87 & 78.2 & 21.8 & & & \\
\hline \multirow{2}{*}{$\begin{array}{l}\text { Who conducted } \\
\text { delivery }\end{array}$} & Midwife & 106 & 94.3 & 5.7 & 4.2 & $1.7-10.2$ & 0.0008 \\
\hline & $\begin{array}{l}\text { Obstetrician or } \\
\text { Clinical Officer }\end{array}$ & 204 & 79.9 & 20.1 & & & \\
\hline \multirow[t]{2}{*}{ Had induction } & Yes & 137 & 89.1 & 10.9 & 2.7 & $1.4-5.1$ & 0.002 \\
\hline & No & 173 & 75.1 & 24.9 & & & \\
\hline \multirow{2}{*}{$\begin{array}{l}\text { Type of } \\
\text { induction used }\end{array}$} & Mechanical & 32 & 81.2 & 18.8 & 0.4 & $0.1-1.2$ & 0.1 \\
\hline & Pharmacological & 105 & 91.4 & 8.6 & & & \\
\hline \multirow{2}{*}{$\begin{array}{l}\text { Augmentation } \\
\text { of labor }\end{array}$} & Yes & 14 & 71.4 & 28.6 & 0.8 & $0.2-2.7$ & 0.8 \\
\hline & No & 159 & 75.5 & 24.5 & & & \\
\hline \multirow{2}{*}{ Type of support for pain relief } & Supportive care & 297 & 81.1 & 18.9 & 0.8 & $1.2-3.6$ & 1.0 \\
\hline & Spinal or epidural analgesia & 13 & 84.6 & 15.4 & & & \\
\hline
\end{tabular}

\section{Multivariate logistic regression of factors influencing mode of birth preference}

Table 3. depicts the results of multivariate logistic regression analysis for the preferred mode of birth for mothers. All the independent variables with $p$ value equal to 0.2 or less were included in the final model of multivariate logistic regression to select determinants of mode of delivery preference and $p$ value of $\leq 0.05$ was considered statistically significant.

Mothers who lived with partners were 4.6 times more likely to prefer SVD (OR: $4.6 ; 95 \%$ CI: $1.0-21.0 ; \mathrm{p}=0.05$ ), those who had cultural beliefs that prohibit certain mode of delivery were almost 10 times more likely to prefer SVD (OR: 10.8; 95\% CI: $3.4-33.7 ; \mathrm{p}<0.0001$ ) while those who were delivered by midwives tended to prefer SVD (OR: 7.3; 95\% CI: $2.1-25.9 ; \mathrm{p}=0.002$ ). This was unlike women whose labor took up-to 12 hours or less who were $50 \%$ less likely to have preferred SVD though the results were more or less marginally significant.

Table 3. Multivariate logistic regression of factors influencing mode of birth preference

\begin{tabular}{|c|c|c|c|c|}
\hline \multirow{2}{*}{ Variable } & \multirow{2}{*}{ OR } & \multicolumn{2}{|l|}{$95 \% \mathrm{CI}$} & \multirow{2}{*}{ P value } \\
\hline & & Lower & Upper & \\
\hline Marital status & 3.1 & 0.7 & 13.1 & 0.1 \\
\hline Lives with partner & 4.6 & 1.0 & 21.0 & 0.05 \\
\hline Income & 0.7 & 0.3 & 1.6 & 0.4 \\
\hline Duration of first stage of labor & 0.5 & 0.2 & 1.1 & 0.08 \\
\hline Duration of second stage of labor & 0.6 & 0.3 & 1.2 & 0.1 \\
\hline Have cultural beliefs that prohibit certain mode of delivery & 10.8 & 3.4 & 33.7 & $<0.0001$ \\
\hline Delivered by midwife & 7.3 & 2.1 & 25.9 & 0.002 \\
\hline I felt less anxious about my labor and birth & 2.0 & 0.9 & 4.8 & 0.1 \\
\hline I felt in control during my birth experience & 0.4 & 0.1 & 1.3 & 0.1 \\
\hline I was not separated from my baby for considerable period of time & 0.6 & 0.2 & 2.4 & 0.5 \\
\hline During labor I received outstanding medical care & 2.0 & 0.8 & 5.0 & 0.1 \\
\hline Giving birth was not painful & 0.7 & 0.3 & 1.7 & 0.4 \\
\hline
\end{tabular}




\section{Discussions}

The results of the study showed that the preferred mode of delivery among postnatal mothers was higher for vaginal delivery at $81.3 \%$ as compared to caesarean delivery at $18.7 \%$ following a study that was conducted in study area. These findings are consistent with results illustrating practices like female genital mutilation and ethnicity did not have influence in the preferred mode of delivery. It is viewed as important indicator of rite of passage into motherhood which has affected acceptance of modern delivery methods for fear of ridicule and stigma from community (Spong et al., 2012). In a study consistent to this that was done in Sweden found out that women are affected by fear and anxiety before birth and stories that make them fear and even desire to have caesarean delivery as their preferred mode. The prevalence of fear of childbirth experience has been reported as $5 \%$ to $30 \%$ in Sweden, Switzerland and Australia.

Approximately $6 \%-10 \%$ of women experience intense fear of labor and birth that is debilitating and disrupts labor process (Birjandi et al., 2017). The finding of these study shows similarity in preference of caesarean delivery from the previous studies.

The findings of the study also shows that level of education influence the mothers preferred mode of delivery with $p$ value $=0.002$ this influence in terms of decision making. These findings are supported by KDHS, 2014 reports which showed that Women level of education has a positive relationship to the age at first birth and also influences women position in decision making on choosing the mode of delivery. The study findings also revealed a statistical significant $(\mathrm{p}<0.0001)$ of living with a partner influence the decision of preferred mode of delivery.

The results of the study showed that there was statistical significant associated with cultural beliefs that prohibit certain mode of delivery ( $\mathrm{p}=0.02$ ). In a study (2015) Zakerihamidi \& Latifnehjad Rousadsari results reported that women perceived normal vaginal delivery as painless mode of delivery facilitating women's physical and mental health promotion as compared caesarean section. In a qualitative study that was conducted in Kenya among the Pastoralist on factors influencing the place of delivery, it emerged that cultural beliefs and practices affected a large proportion of women. They believed that giving birth is a natural process and a traditional birth attendant was enough to deliver them and only get to health care facilities when there is complications (Caulfield, Onyo, \& Byne, 2016). The other variables like religion, FGM practices and tribe did not yield significant results from the study.

The study findings also revealed that there was statistical significant associated with who conducted the delivery by most of the mothers. Most participants preferred their delivery to be conducted by midwife $(p=0.0008)$ as compared with other cadres. However, in a study done in western Kenya on experience of hospital delivery, women common concerns during their childbirth included been abandon by health care providers due to large births occurring, lack of adequate information regarding their care (Warren et al., 2017). Promoting respectful maternal care is being increasingly recognized as a critical element of strategies to improve utilization and quality of maternity care and that all women need and deserve respectful care (Souza et al., 2015).The study findings showed that those mothers who had their labor induced preferred to have a vaginal delivery $(\mathrm{p}=0.002)$.

In a multivariate regression logistic analysis of factors influencing mode of birth preference, the study findings showed that there was statistical significant association of living with partner and the preferred mode of delivery $(\mathrm{p}=0.05)$. This is supported by the study that viewed normal delivery as important indicator of rite of passage into motherhood which has affected acceptance of modern delivery methods for fear of ridicule and stigma from community (Spong et al., 2012). Cultural beliefs that prohibit certain mode of delivery had statistical significant $(\mathrm{p}<0.0001)$. This findings is support with the fact that, decision-making process occurs in light of individual's culture, perceptions, beliefs, insight, personality and how these factors interact. Culture provides a framework for directing a person's behavior on special situation in that individual cultural background affects the expression of concept and the meaning of choosing mode of delivery (Robab, Maryam, Effat, \& Anoshirvan, 2014). The results of the study also revealed statistical significant of mothers preferring to be delivered by midwives $(\mathrm{p}=0.002)$. This findings is supported by the need of Midwives and obstetricians requiring a deep understanding of the emotional aspects of childbirth in order to meet the emotional and psychological needs of laboring women. In a Meta analysis that was done on women's psychological experience on physiological childbirth results illustrated that maintaining self-confidence in early labor, maximizing the benefits of the process of childbirth through physical, emotional and social support of women, enhance their ability of giving birth. Health care professionals need to take a cognizance of empowering the effects of psychological experience of physiological birth (Olza, Leahy-warren, \& Benyamini, 2018).

In focus group discussion there was no statistical significant associated with the mode of delivery, however, in regards to the impact of memories of childbirth with preferred mode of birth expectations could play role in shaping the subjective emotional experience. Studies have found out that positive expectations predicts positive 
experience of childbirth while negative expectations predicts worse e motional effects like posttraumatic stress disorders (Fenorali, Saita, Molgora, \& Accordini, 2016).

\section{Conclusions and Recommendations Conclusions}

Basing on these findings it is evidence that occupation, marital status and living with a partner, previous childbirth experience influence the preferred mode of delivery. Mothers appreciated continuous support during childbirth, involvement in decision making about the progress of labor, good interpersonal communication and respectful maternity care. Mistreatment during childbirth including physical and verbal abuse, the don't care attitude of health care workers, lack of pain management in cases where they should receive pain relief negatively affect childbirth experience and influence the preferred mode of delivery.

\subsection{Recommendations}

The study recommends the County Government of Kericho that midwife be empowered by policy makers in the department of reproductive health in decision making for these mothers during childbirth. Midwives play a key role in during labor and delivery by providing information regarding process, encouragement and emotional support. They also offer information on physical comforting measures. The study also recommends that the hospitals allow the birth companion during the process of childbirth as way of helping them to cope with the labor pains this is in line with focus group discussion.

\section{Competing Interests Statement}

The authors declare that there are no competing or potential conflicts of interest.

\section{References}

Abbaspoor, Z., \& Noori, M. J. (2016). The relationship of socio-demographic and reproductive factors with preferred type of birth. International Journal of Reproduction, Contraception, Obstetrics and Gynecology, 5(6), 1765-1773.

Abebe, F., Berhane, Y., \& Girma, B. (2012) Factors associated with home delivery in Bahirdar, Ethiopia: A case control study. BMC research notes, 5(1), 122 - 134. https://doi.org/10.1186/1756-0500-5-653

Aksoy, M., Aksoy, A. N., Dostbil, A., Celik, M. G., \&Ince, I. ( 2014). The Relationship between Fear of Childbirth and Women's Knowledge about Painless Childbirth. Obstet Gynecol Int. https://doi.org/10.1155/2014/274303

Alexander, A., Mustafa, A., Emil, S. A., Amekah, E., Engmann, C., Adanu, R., \& Moyer, C. A. (2014). Social support during delivery in rural central Ghana: a mixed methods study of women's preferences for and against inclusion of a lay companion in the delivery room. Journal of Biosocial Science, 46(5), 669-685.

Arthur, E. (2012). Wealth and antenatal care use: implications for maternal health care utilization in Ghana. Health economics review, 2(1), 65-78. https://doi.org/10.1186/2191-1991-2-14

Aune, L., Marit Torvik, H., \& Selbe, S. T. (2015). Promoting a normal birth and positive birth experience in Norwegian women's perspective. https://doi.org/10.1016/j.midw.2015.03.016

Bayrampour, H., \& Heaman, M. (2010). Advanced maternal age and the risk of cesarean birth: a systematic review. Birth, 37(3), 219-226. https://doi.org/10.1111/j.1523-536X.2010.00409.x

Bitew, K., Ayichiluhm, M., \& Yimam, K. (2015). maternal satisfaction on delivery service and its associated factors among mothers who gave birth in public health facilities of Ethiopia. https://doi.org/10.1155/2015/460767

Bohren, M. A., Hofmeyr, G. J., Sakala, C., Fukuzawa, R. K., \& Cuthbert, A. (2017). Continuous support for women during childbirth. Cochrane Database Syst Rev. https://doi.org/10.1002/14651858.CD003766.pub6

Bohren, M. A., Hofmeyr, G. J., Sakala, C., Fukuzawa, R. K., \& Cuthbert, A. (2017). Continuous support for women during childbirth. Cochrane Database of Systematic Reviews. https://doi.org/10.1002/14651858.CD003766.pub6

Bohren, M. A., Vogel, J. P., Hunter, E. C., Lutsiv, O., Makh, S. K., \& Souza, J. P. (2015). The mistreatment of women during childbirth in health facilities.

Brodrick, A. (2014). Too afraid to push: Dealing with fear of childbirth. The practicing midwife, 17, 15-17.

Caulfield, T., Onyo, P., \& Byrne, A. (2016). Factors influencing place of delivery for pastoralist women in Kenya: a qualitative study. BMC Women's Health, 16, 52. https://doi.org/10.1186/s12905-016-0333-3 
Chinweuba, A., Okoronkwo, I., Anarado, A., Agbapuonwu, N., Ogbonnaya, N., \& Ihudiebube-Splendor, C. (2018). Differentials in health-related quality of life of employed and unemployed women and with normal vaginal delivery. BMC Women's Health. https://doi.org/10.1186/s12905-017-0481-0

Conesa Ferrer, M. B., Canteras Jordana, M., \& Ballesteros, M. C. (2016). Comparative study analysing women's childbirth satisfaction and obstetric outcomes across two different models of maternity care. BMJ Open, 6 , e011362. https://doi.org/10.1136/bmjopen-2016-011362

County Government of Kericho.Kericho County Strategic Plan 2014 - 2017 County Government of Kericho. Kericho County Annual work Plan 2019-2020.

Dencker, A., Taft, C., Bergqvist, L., \& Berg, M. (2010). Childbirth experience questionnaire (CEQ): development and evaluation of a multidimensional instrument. BMC Pregnancy Childbirth. https://doi.org/10.1186/1471-2393-10-81

El-Zanaty, F., \& Ann, A. (2015). Egypt Demographic and Health Survey Calverton, Maryland: Ministry of Healthy and Population [Arab Republic of Egypt], El-Zanaty and Associates, and Macro International.

Fatemeh, G., Azadeh, A., Eznollah, A., Farideh, S., Mina, M., Shahrzad, Z., .. \& F Fakhr-al-molouk, Y. (2014). Women's knowledge and attitude towards mode of delivery and frequency of caesarean section on mother's request in six public and private hospitals in Tehran, Iran. J. Obstet. Gynaecol. Res., 17(5), 43 - 57

Garthus-Niegel, S., von Soest, T., \& Knoph, C. (2014). the influence of women's preferences and actual mode of delivery on post-traumatic stress symptoms following childbirth: a population- based, longitudinal study. BMC Pregnancy Childbirth, 14, 19. https://doi.org/10.1186/1471-2393-14-191

Hodnett, E. D., Gates, S., Hofmeyer, G. J., \& Sakala, C. (2013). Continuous support for women during childbirth. Cochrane Database Syst Rev. https://doi.org/10.1002/14651858.CD003766.pub5

Kabakian-Khasholian, T., El-Nemer, A., \& Bashour, H. (2015). Perceptions about labor companionship at public teaching hospitals in three Arab countries. International Journal of Gynecology \& Obstetrics, 129(3), 223-226. https://doi.org/10.1016/j.ijgo.2014.12.005

Kalstrom, A., Nystedit, A., \& Hildingsson, I. (2015). The meaning of a positive birth experience: Focus group discussions with women. BMC pregnancy childbirth, 15(251). https://doi.org/10.1186/s12884-015-0683-0

Kalstrom, A., Nystedit, A., \& Hildingsson, I. (2011). A comparative study of experience of childbirth between women who preferred and had caesarean and women who had vaginal delivery. Sexual and reproductive health care, 2, 93-99. https://doi.org/10.1016/j.srhc.2011.03.002

Kamal, S. (2013) Preference for institutional delivery and caesarean section in Bangladesh. Journal of Health, Population and Nutrition, 31(1), 96-107. https://doi.org/10.3329/jhpn.v31i1.14754

Kenya National Bureau of Statistics \& ICF Macro (2015). Kenya demographic and health survey report, 2013-2014. The DHS Program, ICF international Rockville, Maryland, USA.

Kericho County District Health Information System (2018).

Kitui, J., Ewis, S., \& Davey, G. (2013). Factors influencing place of delivery for women in Kenya: analysis of the Kenya Demographic and Health Survey 2008/2009. BMC pregnancy and childbirth, 13(1), 1-18. https://doi.org/10.1186/1471-2393-13-40

Latifnejad-Roudsari, R., Zakerihamidi, M., Merghati-Khoei, E., \& Kazemnejad, A. (2014). Cultural perceptions and preferences of Iranian women regarding cesarean delivery. Iranian journal of nursing and midwifery research, 19(7 Suppl1), S28.

Lavender, T., Hofmeyer, G. J., Neilson, J. P., Kingdon, C., \& Gyte, G. M. (2012). Caesarean section for non-medical reasons at term. Cochrane Database System Review. https://doi.org/10.1002/14651858.CD004660.pub3

Mannava, P., Durrant, K., Fisher, J., Chersich, M., \& Luchters, S. (2015). Attitudes and behaviours of maternal health care providers in interactions with clients: a systematic review. Globalization and health, 11(1), 1-17. https://doi.org/10.1186/s12992-015-0117-9

Martin, C. J. H., \& Martin, C. R. (2014). Development and psychometric properties of the Birth Satisfaction Scale-Revised (BSS-R). Midwifery, 30(6), 610-619.

Mattamundayil, S. A. J., Aranha, M. D. M. S., \& Fernandes, M. P. J. (2017). A study on knowledge, attitudes and demand of labour pain relief techniques among antenatal women in selected hospital in Mangaluru. 
Mazzoni, A., Althabe, F., Gutierrez, L., Gibbons, L., Liu, N. H., Bonotti, A. M., ... \& Belizán, J. M. (2016). Women's preferences and mode of delivery in public and private hospitals: a prospective cohort study. $B M C$ pregnancy and childbirth, 16(1), 1-8. https://doi.org/10.1186/s12884-016-0824-0

Mazzoni, A., Althabe, F., Liu, N., Bonotti, A., Gibbons, L., \&Sánchez, A. (2011). Women's preference for caesarean section: a systematic review and meta-analysis of observational studies. BJOG Int $J$ Obstet Gynaecol. https://doi.org/10.1111/j.1471-0528.2010.02793.x

Mei, J. Y., Afshar, Y., Gregory, K. D., Kilpatrick, S. J., \& Eskaff, T. F. (2016). Birth plans: what matter for birth experiences satisfaction? https://doi.org/10.1111/birt.12226

Ministry of Public Health and Sanitation and Ministry of Medical Services (2012). National Guidelines for quality obstetrics and perinatal care, Kenya.

Mokua, J. A. B. (2014). Factors influencing delivery practices among pregnant women in Kenya: A Case of Wareng'District in Uasin Gishu County, Kenya. Int J Innov Sci Res, 10(1), 50-8.

Montagu, D., Sudhinaraset, M., Diamond-Smith, N., Campbell, O., Gabrysch, S., Freedman, L., ... \& Donnay, F. (2017). Where women go to deliver: understanding the changing landscape of childbirth in Africa and Asia. Health policy and planning, 32(8), 1146-1152. https://doi.org/10.1093/heapol/czx060

Nilsson, L., Thorsell, T., Hertfelt Wahn, E., \& Ekström, A. (2013). Factors influencing positive birth experiences of first-time mothers. Nursing research and practice, 2013. https://doi.org/10.1155/2013/349124

Okeke, T. C., \& Ekwuazi, K. E. (2013). Is there still a place for vacuum extraction (ventouse) in modern obstetric practice in Nigeria. Annals of medical and health sciences research, 3(3), 471-474. https://doi.org/10.4103/2141-9248.122043

Olza, I., Leahy-Warren, P., Benyamini, Y., Kazmierczak, M., Karlsdottir, S. I., Spyridou, A., ... \& Nieuwenhuijze, M. J. (2018). Women's psychological experiences of physiological childbirth: a meta-synthesis. BMJ open, 8(10), e020347. https://doi.org/10.1136/bmjopen-2017-020347

O'Mahony, F., Hofmeyr, G. J., \& Menon, V. (2010). Choice of instruments for assisted vaginal delivery. Cochrane Database of Systematic Reviews, (11). https://doi.org/10.1002/14651858.CD005455.pub2

Renfrew, M. J., McFadden, A., Bastos, M. H., Campbell, J., Channon, A. A., Cheung, N. F., ... \& Declercq, E. (2014). Midwifery and quality care: findings from a new evidence-informed framework for maternal and newborn care. The Lancet, 384(9948), 1129-1145. https://doi.org/10.1016/S0140-6736(14)60789-3

Sandall, J., Soltani, H., Gates, S., Shennan, A., \& Devane, D. (2016). Midwife-led continuity models versus other models of care for childbearing women. Cochrane database of systematic reviews, (4). https://doi.org/10.1002/14651858.CD004667.pub5

Sawyer, A., Ayers, S., Abbott, J., Gyte, G., Rabe, H., \& Duley, L. (2013). Measures of satisfaction with care during labour and birth: a comparative review. BMC pregnancy and childbirth, 13(1), 1-10. https://doi.org/10.1186/1471-2393-13-108

Say, L., Chou, D., Gemmill, A., Tunçalp, Ö., Moller, A. B., Daniels, J., ... \& Alkema, L. (2014). Global causes of maternal death: a WHO systematic analysis. The Lancet global health, 2(6), e323-e333.

Schantz, C., de Loenzien, M., Goyet, S., Ravit, M., Dancoisne, A., \& Dumont, A. (2019). How is women's demand for caesarean section measured? A systematic literature review. PloS one, 14(3), e0213352. https://doi.org/10.1371/journal.pone.0213352

Shorey, S., Yang, Y. Y., \& Ang, E. (2018). The impact of negative childbirth experience on future reproductive decisions: A quantitative systematic review. Journal of advanced nursing, 74(6), 1236-1244.

Størksen, H. T., Garthus-Niegel, S., Vangen, S., \& Eberhard-Gran, M. (2013). The impact of previous birth experiences on maternal fear of childbirth. Acta obstetricia et gynecologica Scandinavica, 92(3), 318-324. https://doi.org/10.1111/aogs.12072

Takehara, K., Noguchi, M., Shimane, T., \& Misago, C. (2014). A longitudinal study of women's memories of their childbirth experiences at five years postpartum. BMC pregnancy and childbirth, 14(1), 1-7. https://doi.org/10.1186/1471-2393-14-221

The Ministry of Health. (2013). The National Patients' Rights Charter 1st edition October -2013.

The Royal Colleague of Obstetrics and Gynaecologists (2011) Normalizing birth and respectful maternity care. 
Tian, X., Wu, J., Li, B., Qin, M., \& Qi, J. (2014). Occurrence of cesarean section and related factors in 40 counties of China from 1978 to 2010. Zhonghua yu fang yi xue za zhi [Chinese journal of preventive medicine], 48(5), 391-395.

Ugwu, N. U., \& de Kok, B. (2015). Socio-cultural factors, gender roles and religious ideologies contributing to Caesarian-section refusal in Nigeria. Reproductive health, 12(1), 1-13. https://doi.org/10.1186/s12978-015-0050-7

Velho, M. B., Santos, E. K. A. D., Brüggemann, O. M., \& Camargo, B. V. (2012). Experience with vaginal birth versus cesarean childbirth: integrative review of women's perceptions. Texto \& Contexto-Enfermagem, 21, 458-466.

Walana, W., Acquah, E. K., Vicar, E., Muhiba, A., \& Dedume, J. (2017). Preference of birth delivery modes among women attending antenatal and postnatal clinics in the tamale metropolis of Ghana. J Preg Child Health, 4(297), 2. https://doi.org/10.4172/2376-127X.1000297

Wang, C. P., Tan, W. C., Kanagalingam, D., \& Tan, H. K. (2013). Why we do caesars: a comparison of the trends in caesarean section delivery over a decade. Ann Acad Med Singapore, 42(8), 408-12.

WHO recommendations on health promotion interventions for maternal and newborn health. Geneva: World Health Organization; 2015

WHO, UNICEF, UNFPA, \&World Bank Group. (2015). The UN population division. Trends in maternal mortality $1990-2015$.

World Health Organization [WHO]. (2015). The global strategy for women's, children's and Adolescent health (2016-2030).

World Health Organization [WHO]. (2016). WHO recommendations on antenatal care for a positive pregnancy experience. Geneva, Switzerland: World Health Organization.

Yuen, J., Painter, I., Abraham, L., Melian, M., \& Denno, D. M. (2014). A comparison of trends in cesarean delivery in Paraguay between 1995 and 2008. International Journal of Gynecology \& Obstetrics, 126(3), $265-271$. https://doi.org/10.1016/j.ijgo.2014.03.030

\section{Copyrights}

Copyright for this article is retained by the author(s), with first publication rights granted to the journal.

This is an open-access article distributed under the terms and conditions of the Creative Commons Attribution license (http://creativecommons.org/licenses/by/4.0/). 